\title{
Herramientas Mágicas / Word Magic Tools de Word Magic Software (Word Magic Tools 2000 Deluxe 2.1.)
}

Dicho software es un paquete de diccionarios de traducción inglés/español que ocupa unos 12 megas en el disco duro de su ordenador, contiene 600.000 entradas y es capaz de desplegar traducciones o sinónimos, además de partes de oración, descriptores, matices y acepciones de palabras con sólo oprimir

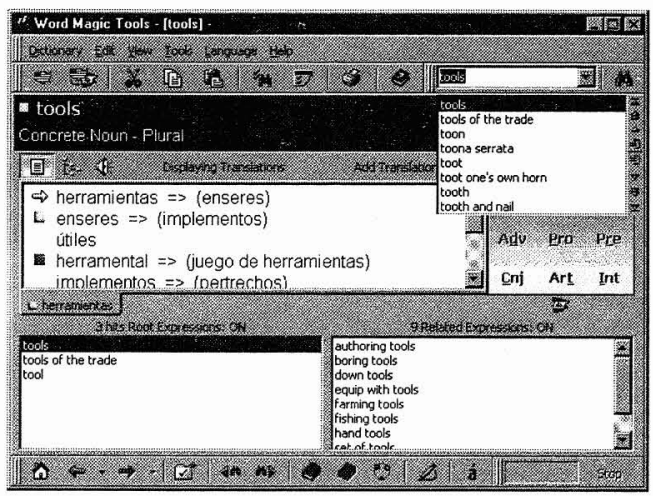
un botón. Su diseño de pantalla en espejo, permite desplegar simultáneamente conjunciones de verbos y realizar búsquedas de expresiones idiomáticas, proverbios, frases adverbiales, locuciones, frases verbales y frases idiomáticas de todo tipo en ambos idiomas, con sus respectivas traducciones y sinónimos.

Word Magic Tools es básicamente una colección de cuatro programas: Diccionario inglés/español de cuatro vías, Conjugador de verbos. Diccionario de sinónimos y Constructor de Expresiones.

Entre las mejoras de la versión anterior, podemos destacar un salto numérico en

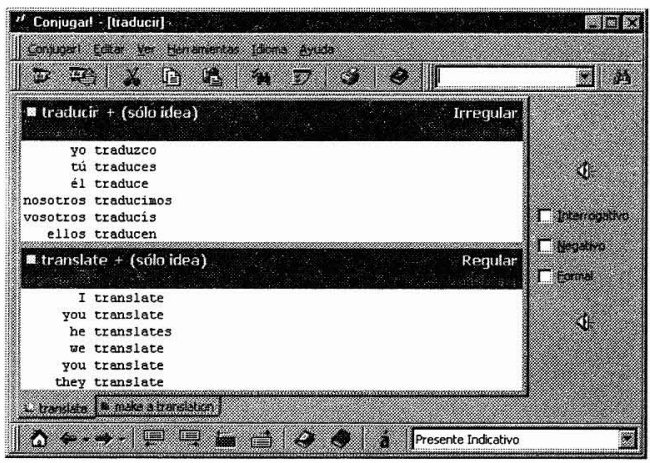
su tamaño, pasando de 480.000 traducciones a 600.000; de 3 a 4 millones de sinónimos; aceptación de diccionarios adicionales de temas técnicos, lo que aumenta las traducciones a 800.000; incorpora caracterís- 


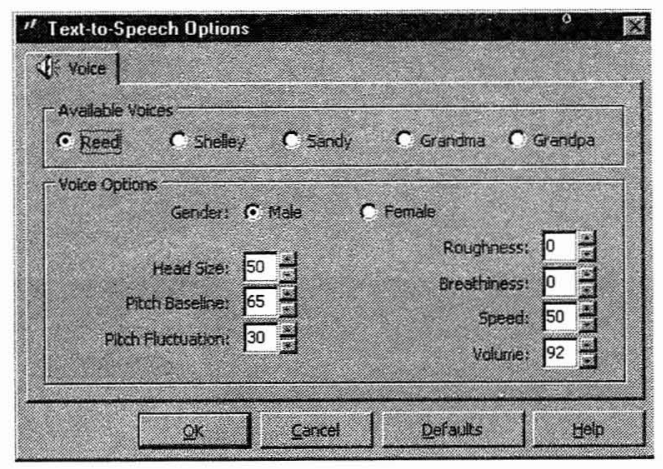

ticas de navegación similares a las utilizadas en Internet; nuevas características y refinamiento en sus opciones de búsqueda, permitiendo que una frase pueda buscarse no solamente por la palabra inicial o final, sino también por cualquier palabra integrada en la frase; está diseñado completamente para 32-bits; y se integra naturalmente con Microsoft Word. Lo que más nos ha llamado la atención de la versión Deluxe, es su pronunciación de voz de entradas en español e inglés (texto-a-voz), que incluso permite escoger el tipo de voz de salida y ajustar una personalizada. No obstante es preciso señalar aquí que la versión incluye voz sintética o enlatada lo que desmejora en sí el sonido de la voz verdadera o real.

\section{I.A "CONEXIÓN MÁGICA"}

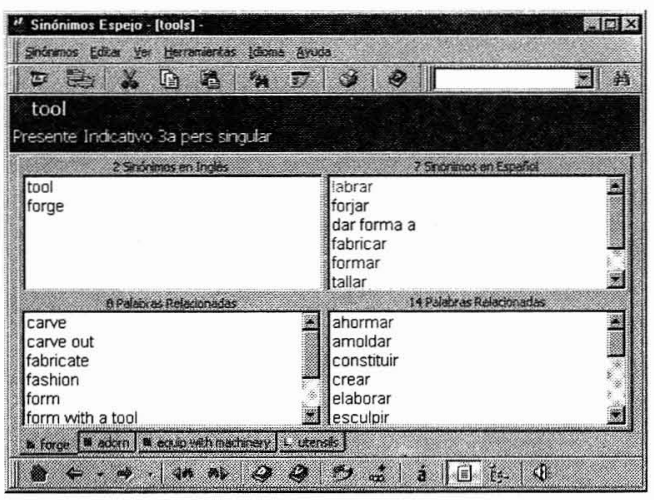

Cualquier palabra puede tener muchas acepciones diferentes, dependiendo del contexto en que esté siendo usada. Se dice que tiene diferentes connotaciones. Word Magic ha intentado separar las palabras dentro del diccionario asignando una página de diccionario para cada acepción. A su vez, a cada página se le asigna una etiqueta descriptiva en español o en inglés, dependiendo de la opción del usuario.

Lo que la Conexión Mágica hace cuando el usuario introduce una palabra o traducción nueva, es interconectar la nueva entrada con todas las pá- 
ginas del diccionario correspondientes, de tal manera que se integrará exactamente en el contexto y connotación tanto en español como en inglés.

Dependerá del usuario escoger la página correcta en ambos idiomas. Se crearán nuevos sinónimos con el mismo significado a partir de la palabra recién agregada. Sinónimos nuevos se crearán también en el idioma contrario. Además, se establecerán nuevas conexiones para la formación de frases que contengan la palabra agregada, para uso en el módulo de Constructor de Expresiones.

Veamos un ejemplo de cómo funciona esta función: Supongamos que queremos agregar una frase nueva al Diccionario de Inglés: "long memory", que significa evocación o reminiscencia. El usuario escribirá "long memory" en el bloque de entrada, y da "reminiscencia" como la traducción en español.

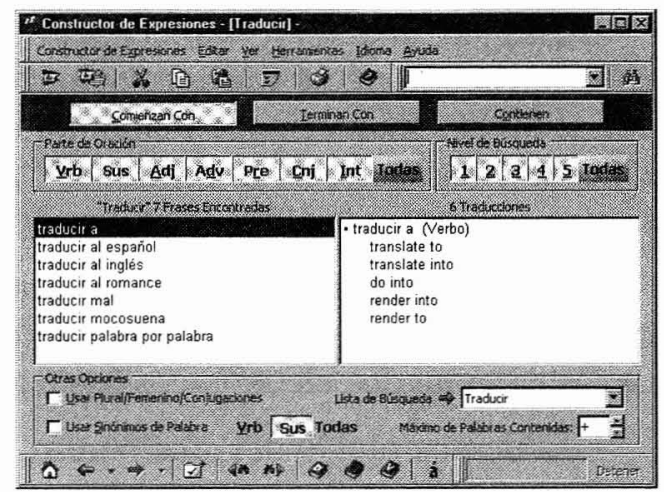
También podemos agregar una frase en español totalmente nueva (inventada), como: "recuerdo de antaño".

Así que obtendremos la siguiente página: "long memory" / n. reminiscencia / recuerdo de antaño. Notaremos que la etiqueta descriptiva de la página recién creada es "Reminiscence". Ahora, si buscamos otra palabra en inglés, que tenga la misma acepción, es muy probable que la Conexión Mágica ya haya encontrado una relación con ella: Buscando, por ejemplo, los sinónimos de la palabra "remembrance", la lista de resultados muestra: "Recollection", "memory", "reminiscence", "evocation", "recall", "retrospection", "memento", y... "long memory".

La Conexión Mágica ha creado una interrelación entre "long memory" y "remembrance", aún cuando "remembrance" nunca fue mencionada por el usuario. Buscando luego una palabra en español que tenga un significado parecido: como "mirada al pasado" ("look to the past"), desplegando sinónimos observamos que "recuerdo de antaño" 
aparece como sinónimo. Y "long memory” aparece también en los resultados de IMagic.

Tengamos en cuenta que ni "recuerdo de antaño" ni "long memory" existían en el Diccionario antes. El usuario las acaba de agregar, y ahora aparecen como sinónimos en sus páginas correspondientes. ¿Qué pasaría si ahora buscáramos directamente en IMagic sinónimos para "recuerdo de antaño"? Aparecen cinco sinónimos en español y once en inglés.

Buscando "memory" con la opción de FINAL en el Diccionario, en usuario encontrará 14 frases relacionadas, incluyendo "long memory", con todas sus traducciones y sinónimos, y también aparecerá en el módulo de Constructor de Expresiones. "Antaño" será la palabra raíz para la nueva expresión agregada en español: "recuerdo de antaño".

En definitiva, una herramienta completa y eficiente para la traducción del inglés al español y del español al inglés, que difiere del resto de los diccionarios electrónicos hasta ahora publicados.

Una demostración del diccionario, aunque muy limitada, se puede bajar de la dirección siguiente: http://www.wordmagic.co.cr/Si se desea obtener la versión operativa, el usuario tendrá que pagar unas 30.000 pesetas por el paquete completo, lo que pone la herramienta un poco fuera del alcance del usuario medio.

Pablo Cancelo (Universidade da Coruña) 